\title{
REVIEWS
}

\section{TEACHERS VOICES 8: EXPLICITLY SUPPORTING READING AND WRITING IN THE CLASSROOM}

EDITED BY ANNE BURNS AND HELEN DE SILVA JOYCE

National Centre for English Language Teaching and Research, Macquarie University, Sydney NSW 2005, 77pp, ISBN 1741381037

This is the most recent book in a series that deals with teaching and learning in the classroom. The specific focus of this book is the explicit support of reading and writing in adult ESL teaching, investigated through classroom projects within the framework of an action research approach. It consists of three sections: the first outlines the theoretical ideas underpinning the book, the second deals with the nature of action research, and the third and longest section presents the participating teachers' own accounts of their research projects. It is accompanied by a DVD containing excerpts of their classroom teaching.

The concept of scaffolding is central to this book. According to Vygotsky's theory, learning is a social process, rather than an individual one. Students learn through working with their peers and other more skilled individuals, such as teachers, and by being challenged. Scaffolding refers to the learning support given to students as part of the learning process. This support is structured by the teacher, and can be withdrawn later, when it is no longer needed. The theory of scaffolding is presented and discussed in the first section, while the practical application of scaffolding to their teaching is discussed in the third section, with the teachers' accounts and reflections on their projects. One practical issue raised by a number of 
teachers was the problem of judging the level of difficulty of materials, so that they were challenging, but within the students' capabilities.

This volume, with the accompanying DVD showing examples of the classroom practice of the teachers featured in the text, could easily be adapted to the needs of a professional development session. There are pre-readings on the theory and research method, a number of teacher accounts to choose from, and an illustration of the teaching practice of each teacher on DVD. It would make for a stimulating session, and one with a practical classroom focus.

For the same reasons, this would be a useful tool for teacher educators. The teachers featured on the DVD are all experienced teachers, and would provide good models for student teachers. The DVD offers the student teacher some useful examples of teaching techniques, such as classroom organization and the structuring of a lesson, and the book has some examples of teaching materials. Each teaching sequence is divided into a series of steps, listed on screen at the beginning of each section, and this series of steps shows the basic structure of the teaching session through which the teacher gives the students a challenging lesson while providing learning support.

For the practising teacher, the most useful and relevant sections of the book are likely to be the teachers' descriptions of classroom activities and their reflections on their teaching practice, in particular the differing approaches to the perennial problem of finding appropriate teaching materials. A comparison of the different classrooms and teaching styles presented in the DVD will also be of great interest for all teachers.

It is always interesting for a teacher to watch another teacher in action, and these teachers have been very generous in allowing us the opportunity to do so. The DVD offers a window into their classrooms, which is a rare and valuable resource, particularly when linked with the same teachers' accounts of their objectives and 
reflections, as given in the book. This aspect of the book/DVD package is its most valuable feature, and should ensure that it is widely used in teacher training and professional development sessions.

on a more general note, this volume reports on a project which involved teachers in the research process, and which linked classroom practice to theories of teaching and learning. The teachers' accounts are the 'teachers' voices' of the series title, voices which as Anne Burns points out, "have been absent too long from the research literature". These voices deserve to be heard for the insights which they offer, not only into the practice of teaching, but into practice informed by theory.

\section{Sarah Ahern}

